\title{
DATOS PARA LA FUNDAMENTACIÓN EMPÍRICA DE LA ESCISIÓN FONEMÁTICA PRESTIGIOSA DE $/ \theta^{\mathrm{s}} /$ EN ANDALUCÍA*
}

\section{INTRODUCGIÓN}

Andalucía es actualmente un ámbito privilegiado para el estudio del contacto dialectal. En contadas oportunidades tiene ocasión el lingüista de enfrentarse al reto de describir una comunidad en la que una variedad vernácula sin prestigio manifiesto entra en relación con tres variedades más prestigiosas ${ }^{1}$ : el estándar nacional, un estándar oral regional de cierta aceptación y una tercera variedad que parece estar desarrollándose velozmente e incorporando elementos prestigiosos de las dos primeras $^{2}$.

* Este trabajo se ha hecho en el marco del Proyecto de Investigación sobre el estudio del Español Urbano de la ciudad de Málaga (ProyectoESESUMA), financiado por la DGICYT (HUM2004-06052-c06-02/filo) y fondos FEDER y del Proyecto de Investigación Estudios sobre el Corpus PRESEEA de Málaga (CORPRESMA), financiado por la DGICYT (HUM2007-65602-C07-03/FILO) y fondos FEDER. Se ha contado asimismo con la financiación de la Consejería de Educación de la Junta de Andalucía (Grupo de Investigación HUM-392). Agradezco a Pedro Martín Butragueño la lectura de una versión previa de este texto y sus oportunos comentarios.

${ }^{1}$ Los patrones tradicionales reductores de la distinción medieval de sibilantes $(\mathrm{s}, \mathrm{z}=\mathrm{s}, \mathrm{z})$ están siendo progresivamente modificados en las variedades urbanas de Andalucía oriental, sobre todo, lo que conlleva la escisión prestigiosa de $/ \theta^{\mathrm{s}} /$ en dos unidades en contraste: $/ \mathrm{s} /$ realizada como estridente y $/ \theta /$ como no estridente, ambas dentales. Cf. J.A. Villena Ponsoda, "La formación del español común en Andalucía. Un caso de escisión prestigiosa", en Fonología instrumental. Patrones fónicos y variación, eds. E. Herrera y P. Martín Butragueño, El Colegio de México, México, 2008, pp. 211-253.

${ }^{2}$ Para la situación sociolingüística de Andalucía en la actualidad, cf. J.A. Villena, art. cit. 
En este contexto, el presente estudio pretende contribuir, siguiendo la huella de los trabajos ya publicados ${ }^{3}$, al mejor conocimiento de las situaciones generales de contacto dialectal y, en particular, a aquellas situaciones generales de contacto en las que interactúan dialectos rurales y urbanos ${ }^{4}$. Los resultados de investigaciones previas ${ }^{5}$ han puesto de manifiesto que los hablantes urbanos de Málaga, Granada y otras áreas orientales de Andalucía, especialmente los jóvenes instruidos de ambos sexos, pronuncian casi sistemáticamente sonidos estridentes [s] y mates $[\theta]$ en estricta correspondencia con la pronunciación

3 Cf. S.M. Bortoni-Ricardo, The urbanization of rural dialect speakers: A sociolinguistic study in Brazil, Cambridge Studies in Linguistics, Cambridge, 1985; Y. Lastra y P. Martín Butragueño, "El modo de vida como variable sociolingüística en el estudio de la ciudad de México", Estructuras en contexto. Estudios de variación y cambio, ed. P. Martín Butragueño, El Colegio de México, México, 2000, pp. 13-43; D. Pesqueira, "Cambio fónico en situaciones de contacto dialectal: el caso de los inmigrantes bonaerenses en la ciudad de México”, en Fonología instrumental, pp. 171-189, o P. Martín Butragueño, "Actitudes y creencias lingüísticas en inmigrantes dialectales. El caso de Madrid", LEA, 15 (1993), 131-141; "La variable (s) en el sur de Madrid", ALM, 33 (1995), 5-57, y "Contacto de dialectos en el mundo hispánico", VR, 54 (1995), 191-210, por citar sólo unos pocos. Para un panorama más completo de los estudios de contacto dialectal dentro y fuera del ámbito hispánico, cf. P. Martín Butragueño, "El contacto de dialectos como motor del cambio lingüístico”, Cambio lingüistico. Métodos y problemas, ed. P. Martín Butragueño, El Colegio de México, México, 2004, pp. 81-144.

${ }^{4}$ Véanse P. Kerswill, Dialects converging. Rural dialects in urban Norway, Oxford University Press, Oxford, 1994, y K. Mattheier (ed.), Dialect and migration in a changing Europe, P. Lang, Berlin, 2000.

5 A.M. Ávila MuÑoz, "La variación reticular e individual de s/z en el vernáculo urbano malagueño. Datos del barrio de Capuchinos", AnMal, 17 (1994), 343-367; J.A. Villena, Proyecto de investigación de las variedades vernáculas de la ciudad de Málaga. Objetivos, métodos y primeros resultados. Informe final para la DGICYT PB 91-0417, 1992-1995, Universidad, Málaga, 1995; "Convergence and divergence in a standard dialect continuum: Networks and individuals in Málaga", Sociolingüistica, 10 (1996), 112-137; "Identidad y variación lingüística: sistema y síntoma en el español andaluz", en Identidades lingüisticas en la España autonómica, eds. G. Bossong y F. Báez de Aguilar, Vervuert-Iberoamericana, Frankfurt/M.-Madrid, 2001, pp. 107-150, y "La formación..."; J.A. Moya Corral y E. Wiedemann, El habla de Granada y sus barrios, Universidad, Granada, 1995; J.A. Moya Corral y M. MartíNEZ, "Reacciones actitudinales hacia la variación dialectal en hablantes granadinos", LEA, 22 (2000), 137-160; I. Cuevas Molina, Variación social y reticular de las consonantes obstruyentes dentales y palatales en el vernáculo urbano malagueño (VUM), tesis doctoral, Universidad, Málaga, 2001, y E. MeLGuizo, "La variación de $/ \theta^{\text {s }} /$ : estudio comparativo de dos muestras de población granadinas", ELUA, 21 (2007), 245-259. 
canónica y la ortografía del estándar nacional ${ }^{6}$. Los hablantes urbanos mayores y menos instruidos y los hablantes rurales, por el contrario, parecen resistir en mayor medida este movimiento de convergencia y se mantienen leales a la pronunciación vernacular de indistinción (seseo, ceceo, ceseo).

Se pretende aquí estudiar, por un lado, cuáles son los correlatos acústicos de las realizaciones meridionales de las unidades escindidas $/ \mathrm{s} /$ y $/ \theta /$ entre los hablantes urbanos y, por otro, qué estrategias de acomodación siguen los hablantes rurales cuando se ven sometidos a condiciones específicas de observación y experimentación.

Las variedades del español que se hablan en Málaga han recibido ya detenida atención y nos son bastante conocidas gracias a los datos recogidos (VUM ${ }^{7}$, PRESEEA-MA ${ }^{8}$, FORDIAL ${ }^{9}$ ) y a los resultados de análisis variados.

\subsection{Objetivos}

El objetivo de este trabajo consiste en investigar las bases acústicas de un proceso fonológico de gran interés que puede desarrollarse en situaciones de contacto dialectal; se trata aquí de la escisión del fonema dental $/ \theta^{\mathrm{s}} /$ en dos unidades perceptualmente distintas: $/ \mathrm{s} / \mathrm{y} / \theta /{ }^{10}$. En la situación estudiada, la distinción

${ }^{6}$ La pronunciación canónica requiere un sonido estridente para la grafía s (sopa ['sopa]) y un sonido no estridente para las grafías $z$ y $c+e, i$ (zapato [ $\theta$ a'pato], cena [' $\theta$ ena], cita [' $\theta$ ita]).

7 J.A. Villena, "Convergence and divergence...".

8 M. Vida Castro (ed.), El español hablado en Málaga. T. 1: Corpus oral para su estudio sociolingüistico. Nivel de estudios bajo, Sarriá, Málaga, 2007; A.M. Ávila Muñoz, J.A. Villena y M.C. Lasarte (eds.), El español hablado en Málaga. T. 2: Corpus oral para su estudio sociolingüístico. Nivel de estudios medio, Sarriá, Málaga, 2008; M.C. Lasarte, J.M. SÁnCHez, A.M. Ávilla y J.A. Villena (eds.), El español hablado en Málaga. T. 3: Corpus oral para su estudio sociolingüistico. Nivel de estudios superior, Sarriá, Málaga, 2009.

9 J.A. Villena, J.A. Moya, A.M. Ávila y M. VidA, "Proyecto de Investigación de la formación de dialectos (FORDIAL)", ELUA, 17 (2003), 607-636.

${ }^{10}$ J.A. VillenA \& M. VidA ("The effect of social prestige on reversing phonological changes: Universal constraints on speech variation in Southern Spain”, en Language variation in Europe. Papers from ICLAVE 2, eds. M. Thelander et al., Uppsala University, Uppsala, 2004, pp. 432-444), al analizar los procesos de convergencia en la dirección del estándar, relacionaron la escisión de este fonema con el prestigio social de la variedad estándar como consecuencia de lo que denominaron Principio de Fasold (cf. 
entre /s/ y / $\theta$ / forma parte del patrón de realización habitual de los hablantes urbanos instruidos. En los hablantes rurales se observa una modificación del patrón habitual de conducta no distinguidor en función de los estilos contextuales. Ante estos hechos, el interés se centra en comprobar si los correlatos acústicos que propician la distinción de [s] y [ $\theta]$ son los mismos en los hablantes urbanos -que mantienen un sistema distinguidor relativamente estable- y los hablantes rurales -que modifican a corto plazo su patrón habitual.

Para lograr estos objetivos, se analiza el corpus de realizaciones obtenidas y se determina el patrón de realización mayoritario dentro de cada grupo y su posible variación diafásica. A continuación, se relacionan los valores de los parámetros acústicos estudiados con la realización percibida ${ }^{11}$, con el fin de determinar qué magnitudes aparecen y en qué grado se modifican para dar lugar a la discriminación de sonidos sibilantes. Por último, se comparan los mecanismos de distinción de sibilantes en las dos variedades estudiadas y se extraen conclusiones generales acerca de la organización de los sonidos sibilantes en las variedades en contacto en Málaga.

El conocimiento de los correlatos acústicos de la distinción meridional de $/ \mathrm{s} /: / \theta /$, tanto en aquellos hablantes que muestran un patrón de realización habitual distinguidor como en los que son habitualmente no distinguidores, será de gran ayuda para comprender mejor el comportamiento de los parámetros acústicos en situaciones de contacto dialectal y cómo la percepción de uno u otro sonido se puede ver alterada por la variación de los valores de dichos parámetros.

Dejamos para más adelante un estudio completo sobre la percepción de estos dos sonidos fricativos basado en una muestra amplia de las poblaciones estudiadas (rural y urbana) con variantes artificialmente creadas o modificadas para satisfacer ciertas exigencias acústicas.

R. FASOLD, "Sociolinguistics in Linguistics", en Sociolinguistics today. International perspectives, eds. K Bolton \& H. Kwok, Routledge, London-New York, 1992, pp. 351-355). Según este principio, determinados rasgos lingüísticos pueden aceptarse por la presión social del prestigio de corriente dominante aunque constituyan flagrantes violaciones de restricciones universales de no marcación.

${ }^{11}$ La clasificación perceptiva de los sonidos ha sido hecha únicamente por la investigadora, en este caso una mujer joven de origen urbano, con estudios superiores, que mantiene contactos frecuentes con el entorno rural. 


\subsection{Hipótesis}

Los sonidos sibilantes se producen a partir de una corriente de aire egresiva y pulmonar que, debido a ciertas condiciones del tracto vocal en el momento de la fonación, genera un sonido turbulento. Shadle distinguió entre obstacle fricatives (cuando la turbulencia es producida por un obstáculo en la salida del aire) y non-obstacle fricatives (cuando la causa de la turbulencia es el estrechamiento del canal fonador) ${ }^{12}$. Esta clasificación fue reinterpretada por Ladefoged y Maddieson como sibilante/no sibilante $^{13}$. Dejando aparte las polémicas surgidas en torno a qué sonidos podrían considerarse sibilantes y cuáles no sibilantes, parece haber un consenso general en el sentido de que los sonidos llamados sibilantes (o estridentes) pueden caracterizarse como "high-pitched and intense" ${ }^{14}$, en tanto que los no sibilantes son "lower pitched and less intense" $(i d$.$) . Este hecho ha$ propiciado que varios investigadores -entre ellos, Laver, Crystal y Martínez Celdrán y Fernández Planas ${ }^{15}$ - sugieran la idea de que los sonidos fricativos se podrían distribuir a lo largo de una escala en cuyos extremos podríamos situar [+ estridente] y [- estridente] o, lo que es lo mismo, mayor o menor intensidad de la realización ${ }^{16}$.

Especialmente si se presta atención a los extremos de este continuo de intensidad (esto es, las realizaciones de $/ \mathrm{s} / \mathrm{y} / \theta /$ ), se aprecian diferencias en la estridencia de las señales. Cuando identificamos una realización de $/ \theta /$, el sonido es claramente menos estridente que cuando percibimos claramente una realización de /s/ (sobre todo si se trata de una realización apicoalveolar $[\mathrm{s}]]^{17}$ ). El problema surge al trasladar esta impresión auditiva a parámetros objetivos y cuantificables. A este respec-

12 "Articulatory-acoustic relationships in fricative consonants", en Speech production and speech modelling, eds. W.J. Hardcastle and A. Marchal, Kluwer Academic Press, Amsterdam, 1990, pp. 187-209.

13 The sounds of the world's languages, Blackwell, Oxford, 1996.

14 J. Laver, Principles of Phonetics, Cambridge University Press, Cambridge, 1994, p. 260.

${ }_{15}$ J. Laver, op. cit., p. 262, D. Crystal, Diccionario de lingüística y fonética, Octaedro, Barcelona, 2000, p. 212 y E. MArtínez Celdrán y A.M. FernánDez Planas, Manual de fonética española, Ariel, Barcelona, 2007, p. 107.

${ }^{16}$ D. Crystal, op. cit.

$17 \mathrm{La}$ [s] es un sonido marcado dentro de este orden, ya que presenta un gesto suplementario de retracción (cf. N. SмiтH, "Dependency Theory meets OT: A proposal for a new approach to segmental structure", Optimality theory, 
to, Martínez Celdrán y Fernández Planas afirman que la intensidad media de las fricativas puede servir como una variable capaz de poner orden en este continuo de intensidad ${ }^{18}$. Según estos autores (véase Figura 1), los sonidos fricativos del español se distribuirían en la escala de intensidad a intervalos regulares de $5 \mathrm{~dB}$ (diferencia que se dobla entre $/ \theta / \mathrm{y} / \mathrm{f} /$ ). En total, 20 $\mathrm{dB}$ separan las realizaciones de $[\mathrm{s}]$ de las realizaciones de $[\theta]^{19}$.

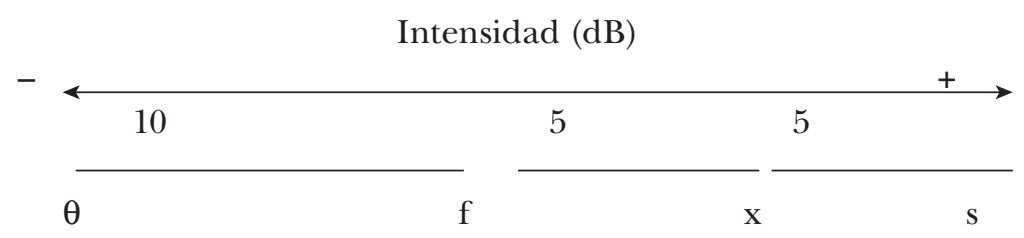

Fuente: Martínez Celdrán y Fernández Planas, Manual de fonética española, p. 107.

Figura 1. Escala de intensidad acústica de las cuatro fricativas del español.

Tomando esta escala como modelo, hemos desarrollado una escala semejante únicamente para los sonidos sibilantes del orden dental. Se trataría de una nueva escala en la que, manteniendo los extremos - de nuevo, la máxima intensidad corresponde a [s] y la mínima a $[\theta]$ - las realizaciones de percepción dudosa, que fonéticamente representamos con $\left[\mathrm{s}^{\theta}\right]$ y $\left[\theta^{\mathrm{s}}\right]$, se situarán en un punto indeterminado de esta gradación (Figura 2). A diferencia de la exacta gradación de la intensidad que se aprecia en la Figura 1, los intervalos de variación de la intensidad en la Figura 2 aún no han sido determinados.

$\mathrm{Al}$ examinar esta escala, que en la comunidad de habla estudiada debería reducirse a cuatro elementos -puesto que, como ya hemos visto, la variante [s] no forma parte de los patrones de realización habituales del español hablado en Málaga- desconocemos en qué medida la intensidad -u otros parámetros implicados en el proceso- se modifican para determinar la percepción

phonology, syntax and acquisition, eds. J.F. Dekkers et al., Oxford University Press, Oxford, 2000, pp. 231-276).

18 Op. cit., p. 107.

19 Las realizaciones de /s/ que Martínez Celdrán y Fernández Planas tuvieron en cuenta para la confección de la escala fueron apicoalveolares [s ]. Como se verá en seguida, al trabajar con realizaciones predorsales, esta escala debe modificar sus valores. 
diferenciada del oyente de cada una de las variantes. En ese sentido, la representación de la Figura 2 es una idealización de la situación real, cuyos detalles aún no han sido precisados. Es muy posible que la intensidad no se incremente a intervalos regulares -como ocurre con la distancia de separación entre la $/ \theta /$ y la /f/ según la escala de Martínez Celdrán y Fernández Planas para el español estándar, que es el doble de la que mantienen, por ejemplo, la /x/ de la /s/- o que las fronteras entre determinados puntos de la gradación sean difíciles de definir y por lo tanto, sus características acústicas puedan llegar a solaparse ${ }^{20}$.

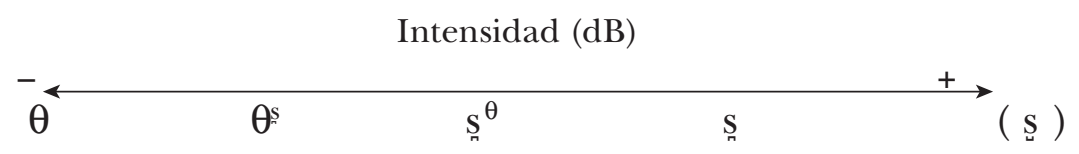

Figura 2. Escala de intensidad acústica de los sonidos del orden dental.

Para comprobar qué variables acústicas fundamentan la escala descrita arriba y hacen posible la percepción diferenciada de las realizaciones, hemos desarrollado un estudio de la pronunciación de los sonidos fricativos dentales en hablantes con diferentes patrones de realización habitual y en diferentes estilos contextuales. Las hipótesis más importantes son las siguientes:

1) Las fricativas dentales del español de la comunidad de habla estudiada se sitúan en un continuo de intensidad. Este continuo se define por una serie de parámetros acústicos que posibilitan las diferentes percepciones: fundamentalmente, la intensidad media y la intensidad máxima de la realización.

2) Los hablantes jóvenes urbanos e instruidos han adoptado un sistema fonológico más o menos estable acomodado al sistema del español estándar nacional mediante la escisión de la unidad coronal $/ \theta^{\mathrm{s}} /$ en dos fonemas independientes: $/ \mathrm{s} /$ y $/ \theta /$ realizados como estridente $[\mathrm{s}]$ el primero y mate $[\theta]$ el segundo. Los correlatos acústicos de ambos fonemas se sitúan, respectivamente, en el

${ }^{20}$ Especialmente en las realizaciones intermedias, $/ \mathrm{s}^{\theta} / \mathrm{y} / \theta^{\mathrm{s}} /$, razón por la cual en este trabajo ambas realizaciones se han reunido bajo la denominación "dudosa". 
extremo (+) y en los alrededores del polo $(-)$, a cierta distancia de $[\mathrm{s}]$.

3) Los hablantes rurales y los hablantes urbanos de clase trabajadora y edad avanzada siguen en menor medida dicho proceso de acomodación. Mantienen un solo segmento $/ \theta^{s}$, cuyas realizaciones alofónicas varían entre los extremos del mencionado continuo. La variación en este continuo está condicionada por el sexo, la clase y el estilo.

4) La variación de estilo determinada por el grado creciente de atención (narración, frases, pares mínimos) condiciona la intensidad media y máxima de las realizaciones, esto es, los parámetros que subyacen en el continuo de variación.

\section{Diseño DE LA PRUEBA}

Hemos seleccionado dos hablantes masculinos de cada núcleo de población estudiado (rural y urbano). Los hablantes rurales son originarios de Cártama, una población del área metropolitana de Málaga situada en la comarca del Guadalhorce. Este municipio, de aproximadamente 20000 habitantes $^{21}$, se localiza a 17 kilómetros de la capital malagueña y consta de once asentamientos, de los que destacan -por número de habitantes e importancia histórica- Cártama Pueblo y Cártama Estación. Los informantes seleccionados pertenecen ambos a Cártama Pueblo, que ejerce como centro administrativo del municipio.

En ambos grupos se buscaron hombres jóvenes (de entre 24 y 31 años) con estudios superiores completos en el momento de la grabación. Las grabaciones se llevaron a cabo en instalaciones convenientemente aisladas acústicamente ${ }^{22}$ y en dos sesiones de grabación diferentes por necesidades de los propios informantes. En las dos sesiones se usó una frecuencia de muestreo de

2120436 en el censo de diciembre de 2008, que comprende todo el municipio (fuente: Instituto Nacional de Estadística).

22 Agradecemos la colaboración del Departamento de Traducción e Interpretación y del Estudio de Grabación de la Facultad de Ciencias de la Información de la Universidad de Málaga por autorizar el uso de sus instalaciones para este proyecto. 
$44100 \mathrm{~Hz}(44,1 \mathrm{kHz})$, calidad habitual de las grabaciones digitales profesionales ${ }^{23}$.

A los cuatro sujetos se les facilitó un texto, que no conocían previamente, y se les pidió que lo leyeran en voz alta y clara. Aunque la totalidad de los informantes desconocía el propósito exacto del experimento y las variables estudiadas ${ }^{24}$, sabían sin embargo que formaba parte de una investigación lingüística y que, por lo tanto, su forma de hablar estaba siendo sometida a examen. El texto en cuestión constaba de tres partes ${ }^{25}$ :

a) Narración. Se decidió prescindir de un párrafo neutro por cuestiones de longitud del experimento e introducir en el primer párrafo una de las variables estudiadas. Dentro de cada párrafo, aparece la variable estudiada un mínimo de diez veces, ya que se ha cuidado específicamente de que, al menos, haya una realización que anteceda a cada una de las vocales del español, tanto tónicas como átonas. El conjunto posee cierta estructura narrativa, ya que en cada uno de los párrafos se relata una pequeña anécdota en relación con las ventajas o inconvenientes de ser extranjero en Málaga. De esta forma, se obtuvieron diez ocurrencias por informante, generando un total de 40 ocurrencias.

b) Frases. A continuación, los informantes procedieron a la lectura de unas frases en las que se repetían las variables estudiadas en la primera parte. En esta segunda parte, no se ha tenido en cuenta la cualidad vocálica, más allá de asegurar que se trata de realizaciones intervocálicas, ni se ha pretendido una distribución tan equilibrada entre las distintas variables como en la sección anterior. En esta sección se contabilizan 139 ocurrencias distribuidas desigualmente entre las variables mencionadas anteriormente.

c) Pares mínimos. Por último, se pidió a los informantes que leyeran una lista de pares mínimos. Se obtuvo un total de 399 realizaciones de /s/ y / $\theta /$ en diferentes contextos $(\mathrm{N}=399)$.

23 Para la grabación del audio se empleó Adobe Premiere $3^{\circledR}$.

${ }^{24}$ Junto a las variables ya comentadas, también se obtuvieron realizaciones de /x/, /t $\int$ / y del segmento /-st-/. Dejamos para más adelante el estudio de estas variables.

${ }^{25}$ El texto completo se adjunta en el Apéndice I. 
3. ANÁLISIS

\subsection{Variables de hablante}

3.1.1. Origen. De un total de 114 realizaciones de /s/ etimológica presentes en el cuestionario, los hablantes de origen rural $-y$, por tanto, usuarios habituales de un patrón de indistinción de $/ \mathrm{s} /: / \theta /-$ produjeron realizaciones interpretadas como $[\theta]$ en 34 ocasiones (29.8\% del total). En otras 14 ocasiones $(12.3 \%$ del total), la interpretación de las realizaciones de /s/ de los hablantes rurales resultó dudosa (o intermedia, que aquí representamos $\operatorname{con} \theta^{\mathrm{s}} \mathrm{os}_{\mathrm{n}}^{\theta}$ ). Así pues, en $42.1 \%$ de las ocasiones, las realizaciones de los hablantes rurales que correspondían a una /s/ etimológica no fueron percibidas como sonidos estridentes identificables con alguna variante de $/ \mathrm{s} /$.

Entre los hablantes de origen urbano -que habitualmente siguen un patrón de distinción de $/ \mathrm{s} /: / \theta /-, 100 \%$ de las realizaciones que se correspondían con una /s/ etimológica fueron percibidas como [s] (vase Tabla 1).

TABLA 1

Efecto del origen en las realizaciones percibidas de /s/ etimológica

\begin{tabular}{|c|c|c|c|c|c|c|}
\hline \multirow{3}{*}{$\begin{array}{l}\text { Realización } \\
\text { percibida }\end{array}$} & \multicolumn{4}{|c|}{ Origen del informante } & \multirow{2}{*}{\multicolumn{2}{|c|}{ Total }} \\
\hline & \multicolumn{2}{|c|}{ urbano } & \multicolumn{2}{|c|}{ rural } & & \\
\hline & $N$ & $\%$ & $N$ & $\%$ & $N$ & $\%$ \\
\hline$[\mathrm{s}]$ & 113 & 100,0 & 63 & 57,9 & 179 & $78^{\prime} 9$ \\
\hline$[\theta]$ & 0 & 00,0 & 34 & $29^{\prime} 8$ & 34 & 15 \\
\hline dudosa & 0 & 00,0 & 14 & $12 ' 3$ & 14 & $6{ }^{\prime} 2$ \\
\hline Total & 113 & 49,8 & 114 & $50 ’ 2$ & 227 & 100 \\
\hline
\end{tabular}

Respecto a las realizaciones correspondientes a una $/ \theta /$ etimológica, tan sólo hubo tres casos (de 172) que fueron claramente percibidas como [s]. De estas tres realizaciones, dos corresponden a hablantes rurales y una proviene de un hablante de origen urbano. Estas tres realizaciones suponen 2.3\% de las correspondientes a una $/ \theta /$ etimológica.

Hay, por lo tanto, $29.8 \%$ de casos de ceceo $^{26}$-todos entre hablantes de origen rural-, que aumenta hasta $42.1 \%$ si tene-

${ }^{26}$ Serían casos en los que se seguiría el patrón de reducción no sibilante 
mos en cuenta aquellos casos en los que la percepción no fue clara. Los casos de seseo ${ }^{27}$ aparecen anecdóticamente en los hablantes de ambos orígenes, constituyendo $2 \%$ del total de realizaciones basadas en una $/ \theta$ / etimológica (véase Tabla 2):

TABLA 2

Efecto del origen en las realizaciones percibidas de / $\theta /$ etimológica

\begin{tabular}{|c|c|c|c|c|c|c|}
\hline \multirow{3}{*}{$\begin{array}{c}\text { Realización } \\
\text { percibida }\end{array}$} & \multicolumn{4}{|c|}{ Origen del informante } & \multirow{2}{*}{\multicolumn{2}{|c|}{ Total }} \\
\hline & \multicolumn{2}{|c|}{ urbano } & \multicolumn{2}{|c|}{ rural } & & \\
\hline & $N$ & $\%$ & $N$ & $\%$ & $N$ & $\%$ \\
\hline [s] & 1 & 1,2 & 2 & 2,3 & 3 & 1,7 \\
\hline$[\theta]$ & 85 & 98,8 & 83 & 96,5 & 3 & 1,7 \\
\hline dudosa & \multicolumn{2}{|c|}{-} & 1 & 1,2 & 1 & 0,6 \\
\hline Total & 86 & 50 & 86 & 50 & 172 & 100 \\
\hline
\end{tabular}

En resumen, la tendencia a la variación en la realización de las sibilantes correspondientes a $s$ etimológica -con una clara tendencia al ceceo entre los hablantes rurales- es congruente con pronunciación patrimonial en esta área geográfica ${ }^{28}$.

Ante estos resultados, podemos afirmar que entre nuestros hablantes de origen rural hay una fuerte tendencia al ceceo (casi 30\% de las ocasiones), en tanto que entre los hablantes de origen urbano se manifiesta una clara correspondencia entre etimología y realización (esto es, practicarían casi $100 \%$ de las ocasiones una distinción meridional de sibilantes).

Estos datos confirman los de Ávila Muñoz ${ }^{29}$ con respecto a la influencia del origen del informante en el mantenimiento de

(RNS). Este patrón consiste en la reducción de la pareja de sibilantes etimológicas (ts, dz frente a s, z) a favor de un único sonido no sibilante [ $\theta$ ]. J.A. Villena ("Andaluz oriental y andaluz occidental. Estandarización y planificación en ¿una o dos comunidades de habla?”, en Estudios sociolingüisticos del español de España y América, coords. A.M. Cestero, I. Molina y F. Paredes, 2006, p. 244) sitúa este patrón en la base de la pirámide jerárquica de las variedades del español de Andalucía, junto a otros rasgos representativos de las variedades vernaculares, lo que nos da una idea precisa del grado de estigmatización del fenómeno respecto al español estándar.

${ }_{27} \mathrm{El}$ seseo, o reducción a favor del sonido sibilante (RS), consiste en la solución sibilante [s] de la mencionada reducción.

${ }^{28}$ Véase A. Narbona, R. Cano y R. Morillo, El español hablado en Andalucía, Fundación José Manuel Lara, Sevilla, 2003, p. 155.

29 "La variación reticular...". 
un patrón de realización reductor. Desde el punto de vista del avance de la distinción meridional ${ }^{30}$, los datos que aquí se ofrecen confirman que el proceso está mucho más consolidado en las comunidades urbanas que en las rurales.

3.1.2. Estilo. Para observar la posible influencia de la variación diafásica en la distinción de sibilantes, se tuvieron en cuenta tres estilos de lectura: pares mínimos, frases y texto (véase Apéndice I). El comportamiento de los dos grupos de hablantes estudiados en relación con el estilo varió significativamente. Mientras que los hablantes de origen rural modificaban en gran medida su conducta al aumentar la formalidad (véase Tabla 3), los hablantes de origen urbano desarrollaron un comportamiento mucho más homogéneo a lo largo de los tres estilos estudiados.

TABLA 3

Efecto del estilo en la realización percibida de /s/ etimológica en los hablantes de origen rural

\begin{tabular}{|l|c|c|c|}
\hline Estilo & {$[\theta]$} & {$[\mathrm{s}]$} & {$\left[\theta^{\mathrm{s}}, \mathrm{s}^{\theta}\right]$} \\
\hline Texto & 55.0 & 35.0 & 10.0 \\
\hline Frases & 32.9 & 54.3 & 12.9 \\
\hline Pares mínimos & 0.0 & 87.5 & 12.5 \\
\hline
\end{tabular}

Chi $^{2}$ sig. $=, 002$.

En las realizaciones de los hablantes rurales, llama especialmente la atención el descenso del porcentaje de /s/ etimológica percibida como $[\theta]$ conforme aumenta la formalidad del estilo de lectura: $55 \%$ en la lectura del texto; $32.9 \%$ en la lectura de frases y $0 \%$ en los pares mínimos. Este decrecimiento puede aportar datos sobre el alto grado de conciencia lingüística que manifiestan los hablantes rurales ante la indistinción de sibilantes.

Frente a esta situación, los hablantes de origen urbano relacionan de forma categórica la realización (al menos, la realización percibida en este estudio) con la etimología correspondiente. Únicamente hay un caso -en el estilo de pares mínimos- en el que se percibió un sonido estridente asociado a una etimología mate.

30 "Andaluz oriental y andaluz occidental...". 


\subsection{Variables acústicas}

3.2.1. Duración. En los datos estudiados, no es posible establecer una relación directa entre la duración del segmento fricativo y su percepción ${ }^{31}$. Para determinar este parámetro se procedió a medir el tiempo (en segundos) de ejecución de cada sonido. Las mediciones se hicieron con Praat 5.0.2.42 ${ }^{\odot 32}$, teniendo en cuenta el momento de inicio y final en el espectrograma del llamado "ruido" correspondiente a la fricación propia de los sonidos sibilantes. Ya que todas las realizaciones consideradas se encontraban en contexto intervocálico, la presencia en el espectrograma de los formantes propios de la articulación vocálica ayudó a delimitar con mayor precisión el inicio y final de la sibilancia.

Los resultados de las realizaciones de los hablantes de origen tanto rural como urbano muestran un aumento gradual de la duración conforme se incrementa la formalidad del estilo de lectura, como era esperable (Figura 3). Este progresivo alargamiento del segmento sibilante ocurre tanto en las realizaciones de /s/ etimológica como de / $\theta /$, siendo las realizaciones de los hablantes de origen urbano por lo general más largas que las de los hablantes rurales (ANOVA sig. $=, 000$ ):

31 Entre los estudios anteriores que, con resultados desiguales, han tenido en cuenta la duración como un factor en la distinción de sibilantes, cabe citar a A. Jongman, "Duration of frication noise required for identification of English fricatives", Journal of the Acoustical Society of America, 85 (1989), pp. 1718-1725; M. Gordon, P. Barthmaier y K. Sands, "A cross-linguistic study of voiceless fricatives", Journal of the International Phonetic Association, 2002, núm. 32, 141-174; L. Jesus, L. \& C. Shadle, "A parametric study of the spectral characteristics of European Portuguese fricatives", Journal of Phonetics, 30 (2002), 437-464; D. Recasens y A. Espinosa, "An electropalatographic and acoustic study of affricates in two Catalan dialects", Journal of the International Phonetic Association, 2007, núm. 37, 143-172, o M. Jones \& F. Nolan, "An acoustic study of North Welsh voiceless fricatives", Proceedings of the $16^{\text {th }}$ International Congress of Phonetic Sciences, eds. J. Trouvain \& W. Barry, Saarbrücken, 2007, pp. 873-876.

32 Paul Boersma y David Weenink (1992-2008): www.fon.hum.uva.nl/ praat (última consulta: 20 de abril de 2009). 


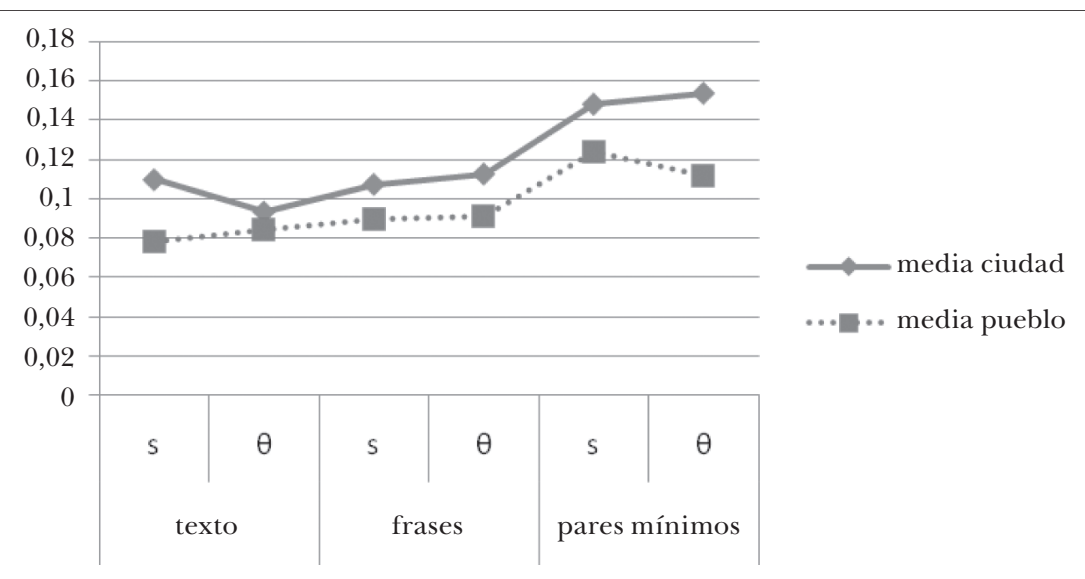

Figura 3. Efecto del estilo en la duración de las realizaciones.

3.2.2. Intensidad media. Entendemos por intensidad media de la realización el valor medio (en decibelios) de los valores de la intensidad de una determinada realización en un cierto período de tiempo. El programa PRAAT ${ }^{\circledR}$ ofrece tres métodos diferentes para calcular la media de intensidad. Se ha optado por el método "energía" por estar su valor próximo al nivel de presión sonora (sound pressure level). De esta forma, se facilita una medición lo más objetiva posible del parámetro. Teniendo en cuenta los estudios anteriores sobre diferenciación de fricativas mates y estridentes ${ }^{33}$, y especialmente la escala de intensidad de Martínez Celdrán y Fernández Planas ${ }^{34}$ comentada anteriormente, la intensidad media de las realizaciones se perfila como un

33 La intensidad de las realizaciones ha sido tenida en cuenta en numerosos estudios sobre la naturaleza de los sonidos fricativos: véase S. BEHRENS $\&$ S.E. Blumstein, "On the role of the amplitude of the fricative noise in the perception of place of articulation in voiceless fricative consonants", Journal of the Acoustic Society of America, 1988, núm. 84, 861-867; L. Jesus y C. SHAdLe, art. cit.; M. Jones, "An experimental acoustic study of dental and interdental non-sibilant fricatives in the speech of a single speaker", Cambridge Occasional Papers in Linguistics, 2005, núm. 2, 109-121; y Jones \& Nolan, "An acoustic study...", entre otros. Para el español: J. Gurlekian, "Recognition of the Spanish fricatives /s/ and /f/", Journal of the Acoustical Society of America, 70 (1981), 1624-1627; M.J. Albalá y V. Marrero, "La intensidad de los sonidos españoles”, RFE, 75 (1995), 105-132, y E. Martínez Celdrán y A.M. FerNÁNDEZ Planas, op. cit.

${ }^{34}$ Op. cit., p. 117. 
buen candidato para explicar acústicamente la diferenciación perceptiva en las dos comunidades malagueñas analizadas. Sin embargo, esta variable presenta un comportamiento completamente distinto en los dos grupos estudiados.

Por una parte, en las realizaciones de los hablantes urbanos, los datos de la intensidad media ofrecen diferencias significativas conforme a lo esperado (véase Tabla 4). Las realizaciones percibidas como [s] muestran una media de intensidad casi $10 \mathrm{~dB}$ por encima de aquellas que fueron percibidas como $[\theta]$ :

\section{TABLA 4}

Intensidad media (dB) obtenida en las realizaciones de los hablantes urbanos

\begin{tabular}{|l|c|c|}
\hline \multicolumn{1}{|c|}{ Percepción } & Intensidad media $(d B)$ & Desv. típica \\
\hline$[\mathrm{s}](\mathrm{N}=114)$ & 69,13 & 2,51 \\
\hline$[\theta](\mathrm{N}=85)$ & 60,27 & 2,97 \\
\hline
\end{tabular}

T-test sig. $=, 000$.

En los hablantes rurales, sin embargo, los valores medios obtenidos en las realizaciones percibidas (véase Tabla 5) no indicaron diferencias de intensidad media. La prueba de Tuckey incluye los valores medidos como parte de un único grupo homogéneo, en tanto que la prueba de análisis de varianza produce resultados no significativos para esta relación:

TABLA 5

Intensidad media (dB) obtenida en las realizaciones de los hablantes rurales

\begin{tabular}{|l|c|c|}
\hline \multicolumn{1}{|c|}{ Percepción } & Intensidad media $(d B)$ & Desv. típica \\
\hline$[\mathrm{s}](\mathrm{N}=68)$ & 64,19 & 5,08 \\
\hline$[\theta](\mathrm{N}=117)$ & 63,54 & 4,34 \\
\hline Dudosa $(\mathrm{N}=15)$ & 63,50 & 4,95 \\
\hline
\end{tabular}

ANOVA sig. $=, 677$.

En la escala de intensidad propuesta por Martínez Celdrán y Fernández Planas (ibid., p. 117), /s/ (apicoalveolar) y / $\theta /$ aparecían separadas por $20 \mathrm{~dB}$. Esta distancia se reduce en los hablantes urbanos de la muestra estudiada, que distinguen entre / $\theta /$ 
y /s/ (predorsal), a $10 \mathrm{~dB}$. Como se aprecia, la modificación del punto de articulación introduce importantes cambios en la escala de las fricativas y disminuye significativamente la distancia entre ambos sonidos.

En cualquier caso, los datos obtenidos muestran que la intensidad media no es un parámetro que los hablantes rurales usen para diferenciar entre /s/ y / $\theta /$. Si intentáramos representar en una escala la intensidad media de las realizaciones de los hablantes rurales y su correspondiente percepción, las categorías resultantes se superpondrían. Sin embargo, la identificación de determinadas realizaciones de hablantes rurales como /s/ y / $\theta /$ en estilos cuidadosos y en estricta correspondencia con la ortografía y la pronunciación canónica de la variedad estándar nos indica que, con gran probabilidad, estos hablantes habitualmente no distinguidores están empleando una técnica alternativa -no basada en la intensidad media- para producir una discriminación de sibilantes eficaz. Como posibles factores explicativos de esta diferenciación, hemos analizado la intensidad máxima, la frecuencia de inicio de la fricación, la frecuencia de máxima intensidad, la frecuencia de inicio de la fricación y el centro de gravedad de las realizaciones.

3.2.3. Intensidad máxima. La intensidad máxima de la realización se ha medido teniendo en cuenta el valor máximo que alcanza la representación espectral del segmento fricativo en el eje de ordenadas espectral ${ }^{35}$. Con objeto de determinar con la mayor precisión posible las características del momento de máxima intensidad de la realización percibida, se han tomado dos medidas en el espectro de la realización. A diferencia del espectrograma -en el que se ponen en relación el tiempo con la frecuencia-, en el espectro las magnitudes confrontadas son la intensidad y la frecuencia. Este hecho permite observar con mayor detalle cómo varía la intensidad a lo largo de la realización, sin tener en cuenta el factor tiempo. La gráfica que resulta del cálculo del espectro de la realización nos indica dos medidas clave en este estudio: (a) la intensidad máxima de la realización y (b) la frecuencia a la que se alcanza esta intensidad máxima. Ambas medidas se podían haber tomado en el espectrograma atendiendo a criterios como la mayor intensidad de la

${ }^{35}$ Las secciones espectrales (spectral slice) de las realizaciones se han calculado con un rango dinámico de $50 \mathrm{~dB}$ y un ancho de banda total de $22050 \mathrm{~Hz}$. 
mancha oscura correspondiente a la señal, en el caso de la frecuencia de máxima intensidad o el punto más alto en la curva de intensidad -que opcionalmente podemos representar sobre el espectrograma-, para la variable de intensidad máxima. Se decidió realizar las mediciones sobre el espectro para lograr la mayor objetividad posible en los datos.

Las realizaciones de los hablantes rurales (véase Tabla 6) muestran una diferencia de intensidad máxima de aproximadamente $10 \mathrm{~dB}$ entre los sonidos percibidos como [s] y los percibidos como $[\theta]$. La prueba de Tuckey agrupa las realizaciones dudosas con el grupo de los sonidos percibidos como [s].

TABla 6

Intensidad máxima $(d B)$ en las realizaciones percibidas de los hablantes rurales

\begin{tabular}{|l|c|c|}
\hline \multicolumn{1}{|c|}{ Percepción } & Intensidad máxima $(d B)$ & Desv. típica \\
\hline$[\mathrm{s}](\mathrm{N}=68)$ & 25,06 & 7,60 \\
\hline$[\theta](\mathrm{N}=117)$ & 14,21 & 8,85 \\
\hline dudoso $(\mathrm{N}=15)$ & 21,24 & 7,57 \\
\hline
\end{tabular}

ANOVA sig. $=, 000$.

En los hablantes urbanos (véase Tabla 7), observamos que la distribución de datos respecto al pico de máxima intensidad del espectro varía ligeramente. En este caso, la distancia media en decibelios entre los picos máximos de los espectros de las realizaciones percibidas como [s] y [ $\theta$ ] se amplía hasta $15 \mathrm{~dB}$. Si bien tanto el pico del espectro en las realizaciones percibidas como [ $\theta$ ] como en las percibidas como [s] aumentan en intensidad respecto a las realizaciones de los hablantes rurales, el aumento de la distancia entre ambos máximos parece fundamentarse en el aumento del pico de intensidad en las realizaciones percibidas como /s/ (25,06 frente a 35,14). En consecuencia, a pesar de esta diferencia -y teniendo en cuenta que la desviación típica de la media es mayor en los hablantes habitualmente no distinguidores-, tanto los hablantes urbanos como los rurales parecen utilizar la intensidad máxima de sus realizaciones para la diferenciación de $/ \mathrm{s} / \mathrm{y} / \theta /$. 
TABLA 7

Intensidad máxima $(d B)$ en las realizaciones percibidas de los hablantes urbanos

\begin{tabular}{|l|c|c|}
\hline \multicolumn{1}{|c|}{ Percepción } & Intensidad máxima $(d B)$ & Desv. típica \\
\hline$[\mathrm{s}](\mathrm{N}=114)$ & 35,14 & 3,84 \\
\hline$[\theta](\mathrm{N}=85)$ & 19,99 & 5,78 \\
\hline
\end{tabular}

T-test sig. $=, 000$.

3.2.4. Frecuencia de inicio de fricación. Para medir la frecuencia de inicio de la fricación, hemos tomado como referencia la representación espectrográfica de la sibilante. El ruido fricativo aparece representado en el espectrograma como una mancha carente de armónicos que se mantiene a lo largo de la realización de la fricativa. Se tomó como frecuencia de inicio de la fricación el punto en el que comienza esta mancha.

Este parámetro muestra un comportamiento claramente diferenciado según la procedencia del hablante. Las realizaciones producidas por hablantes de origen rural identificadas como [s] muestran una frecuencia media de inicio de la fricación de $2770 \mathrm{~Hz}$ frente a los $1903 \mathrm{~Hz}$ de las realizaciones interpretadas como [ $\theta$ ] (véase Tabla 8). Frente a estos datos, los hablantes urbanos (véase Tabla 9) muestran un comportamiento diferente: en este grupo, la frecuencia de inicio de la fricación es menor para las realizaciones interpretadas como [s] $(2749 \mathrm{~Hz})$ que para las que fueron interpretadas como [ $\theta](3119 \mathrm{~Hz})$. En ambos casos, las diferencias entre las medias son significativas.

Al hacer la prueba de Tuckey sobre los datos de los hablantes rurales obtenemos dos subgrupos homogéneos, en los que las realizaciones clasificadas perceptivamente como dudosas quedan, por sus valores y al igual que ocurría con la intensidad máxima, más próximas al grupo de las percibidas como [s]. Estas realizaciones, pese a la notable diferencia que las separa en lo tocante a la frecuencia de inicio de la fricación, no han sido identificadas inequívocamente como /s/ debido probablemente a la ausencia de otros factores acústicos necesarios para percibir un sonido estridente. Así pues, si la diferenciación de sibilantes se fundamentara únicamente (o prioritariamente) sobre esta variable, muchas de las percepciones dudosas deberían haber sido interpretadas como estridentes. Este dato hace pensar que hay otros factores acústicos implicados en la diferenciación de sibilantes, como se verá más adelante. 
TABLA 8

Frecuencia media de inicio de la fricación en las realizaciones de los hablantes rurales

\begin{tabular}{|l|c|c|}
\hline \multicolumn{1}{|c|}{ Percepción } & Frecuencia de inicio $(\mathrm{Hz})$ & Desv. típica \\
\hline$[\mathrm{s}](\mathrm{N}=68)$ & 2770 & 755 \\
\hline$[\theta](\mathrm{N}=117)$ & 1903 & 660 \\
\hline Dudoso $(\mathrm{N}=15)$ & 2684 & 950 \\
\hline
\end{tabular}

ANOVA sig. $=, 000$.

TABLA 9

Frecuencia media de inicio de la fricación en las realizaciones de los hablantes urbanos

\begin{tabular}{|l|c|c|}
\hline \multicolumn{1}{|c|}{ Percepción } & Frecuencia de inicio $(\mathrm{Hz})$ & Desv. típica \\
\hline$[\mathrm{s}](\mathrm{N}=114)$ & 2749 & 633 \\
\hline$[\theta](\mathrm{N}=85)$ & 3119 & 533 \\
\hline
\end{tabular}

T-test sig. $=, 000$.

3.2.5. Frecuencia de máxima intensidad. La medición de la frecuencia de máxima intensidad de la realización se ha efectuado sobre el eje de abscisas del espectro del segmento fricativo (que representa la frecuencia, en tanto que el eje de ordenadas marca la intensidad de la realización).

Si relacionamos la frecuencia de máxima intensidad medida en Herzios con la realización percibida en las realizaciones producidas por los hablantes rurales (véase Tabla 10), observamos que las diferencias de medias no son grandes, si bien son estadísticamente significativas $(\mathrm{sig}<.05)$. La prueba de Tuckey aplicada a esta muestra no distingue subgrupo alguno.

TABLA 10

Frecuencia de máxima intensidad media ( $\mathrm{Hz}$ ) en las realizaciones percibidas en hablantes de origen rural

\begin{tabular}{|l|c|c|}
\hline \multicolumn{1}{|c|}{ Percepción } & Frecuencia de máxima intensidad $(\mathrm{Hz})$ & Desv. típica \\
\hline$[\mathrm{s}](\mathrm{N}=68)$ & 5984 & 1001 \\
\hline$[\theta](\mathrm{N}=117)$ & 5442 & 1869 \\
\hline Dudoso $(\mathrm{N}=15)$ & 5110 & 1115 \\
\hline
\end{tabular}

ANOVA sig. $=, 038$. 
En los hablantes de origen urbano (véase Tabla 11), la frecuencia a la que se alcanzan las correspondientes intensidades máximas tiene mayor relación y más significativa con la realización percibida. Llama la atención de nuevo el hecho de que, al igual que ocurría con la frecuencia de inicio de la fricación, el comportamiento de los datos medios difiere entre los grupos. En los hablantes rurales, las realizaciones con los valores de frecuencia de máxima intensidad más elevados fueron en general interpretadas como [s] , en tanto que las realizaciones de los hablantes urbanos con frecuencia de máxima intensidad más alta se interpretaron en su mayoría como realizaciones mates ${ }^{36}$.

TABLA 11

Frecuencia de máxima intensidad (Hz) en las realizaciones percibidas en hablantes de origen urbano

\begin{tabular}{|c|c|c|}
\hline Percepción & Frecuencia de máxima intensidad $(\mathrm{Hz})$ & Desv. típica \\
\hline$[\mathrm{s}](\mathrm{N}=114)$ & 5937 & 1137 \\
\hline$[\theta](\mathrm{N}=85)$ & 6554 & 1324 \\
\hline
\end{tabular}

T-test sig. $=, 001$.

3.2.6. Centro de gravedad. El centro de gravedad o Center of Gravity $(C O G)$ de una realización es, según Ladefoged, "equivalent to the point on which a piece of cardboard with the shape of the curve would balance in a pin" ${ }^{37}$. Podría definirse, por tanto, como la frecuencia (en $\mathrm{Hz}$ ) óptima para lograr el equilibrio de la intensidad de la realización, dejando a uno y otro lado de su valor en el espectro aproximadamente la misma cantidad de intensidad. En estudios anteriores ${ }^{38}$, los centros de gravedad registrados han sido generalmente más altos para /s/ que para el resto de sonidos fricativos. Con el objetivo de comprobar el posible efecto del

${ }^{36}$ El comportamiento ligeramente anómalo de esta variable al comparar los dos grupos estudiados (con tendencias medias opuestas) apunta en la dirección de que esta variable no explicaría satisfactoriamente la diferente percepción de las realizaciones fricativas.

37 Phonetic data analysis: An introduction to instrumental phonetic fieldwork, Blackwell, Oxford, 2003, p. 156.

38 M. Gordon, P. Barthmaier \& K. Sands, "A cross linguistic study...”; M. Zygis \& S. Hamann, "Perceptual and acoustic cues of Polish coronal fricatives", Proceedings of the $15^{\text {th }}$ International Congress of Phonetic Sciences, eds. M.J. Solé et al., Causal Productions, Barcelona, 2003, pp. 395-398; M. Jones, "An experimental acoustic...", y M. Jones \& F. Nolan, "An acoustic study of North...". 


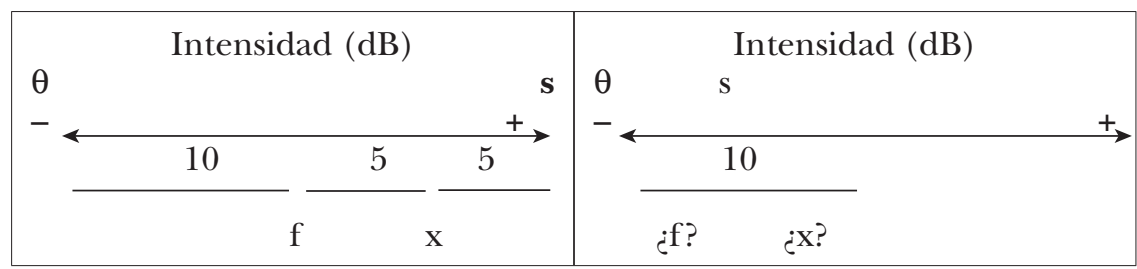

Figura 4. Escala de intensidad de sonidos fricativos del español estándar (izquierda, tomado de Martínez Celdrán y Fernández Planas, "Manual de fonética española", p. 117) y adaptación para el sistema meridional de distinción (derecha).

comportamiento de esta variable en la explicación de la diferenciación perceptiva de los sonidos estudiados, se procedió a realizar las mediciones correspondientes en cada realización.

El programa PRAAT $^{\circledR}$ ofrece la posibilidad de calcular el centro de gravedad de las realizaciones estudiadas a partir de su respectivo espectro, procedimiento elegido aquí para hallar este valor. En nuestro estudio, el centro de gravedad por sí mismo no resulta un factor significativo para explicar la diferente percepción de sonidos mates y estridentes en los hablantes urbanos (véase Tabla 12).

TABLA 12

Centro de gravedad y realización percibida en hablantes urbanos

\begin{tabular}{|l|c|c|}
\hline Percepción & Centro de gravedad $(\mathrm{Hz})$ & Desv. típica \\
\hline$[\mathrm{s}](\mathrm{N}=114)$ & 6239 & 512 \\
\hline$[\theta](\mathrm{N}=85)$ & 6413 & 1425 \\
\hline
\end{tabular}

T-test sig. $=, 284$

En los hablantes de origen rural (véase Tabla 13), la significación del centro de gravedad varía sustancialmente. Lo primero que nos llama la atención es que los centros de gravedad muestran valores -tanto en las realizaciones percibidas como [s] como en las que fueron interpretadas como $[\theta]-$ sensiblemente más bajos que los observados en las realizaciones de hablantes urbanos. Igualmente, la desviación típica de los datos es mayor. La prueba de Tuckey agrupa las realizaciones dudosas con las que fueron percibidas como $[\theta]$. 
TABLA 13

Centro de gravedad y realización percibida en hablantes rurales

\begin{tabular}{|c|c|c|}
\hline Percepción & Centro de gravedad $(\mathrm{Hz})$ & Desv. típica \\
\hline$[\mathrm{s}]$ & 4503 & 2090 \\
\hline$[\theta]$ & 3271 & 2241 \\
\hline dudoso & 3680 & 2092 \\
\hline
\end{tabular}

ANOVA sig. $=, 001$.

A partir de los datos ya conocidos -intensidad media, intensidad máxima y centro de gravedad-podemos proponer una representación gráfica que explicaría la relación entre los valores medios de estos parámetros y la significación del centro de gravedad en la discriminación de $/ \mathrm{s} /$ y $/ \theta /$ en el grupo de hablantes rurales. Las realizaciones de los hablantes rurales percibidas como [s] mostrarán una distribución de la energía menos uniforme que las percibidas como $[\theta]$-tal y como indican los valores similares de intensidad media de $[\mathrm{s}]$ y $[\theta]$ pero divergentes en intensidad máxima-, lo que influiría en la separación de los centros de gravedad de ambas percepciones (véase Figura 5).
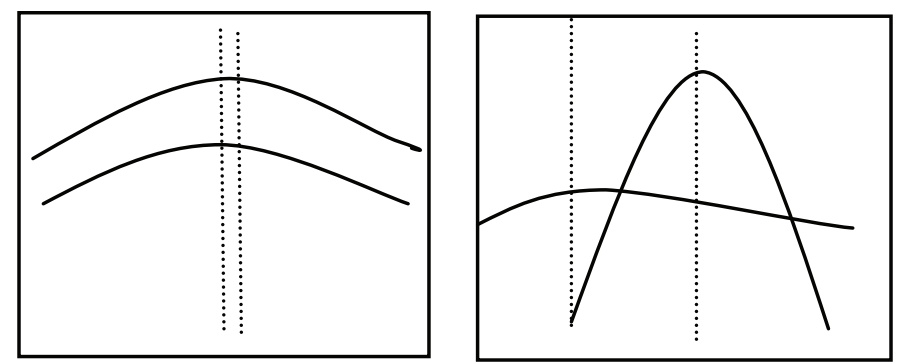

Figura 5. Representación gráfica interpretativa que muestra la posibilidad de que los centros de gravedad sean similares en realizaciones con diferente intensidad media (izquierda; este es el caso de las realizaciones de los hablantes urbanos) y se separen cuando la intensidad media es similar (derecha; en las realizaciones de los hablantes rurales).

En los hablantes urbanos, las realizaciones se diferencian por su intensidad media y máxima, pero muestran un centro de gravedad similar. Una distribución uniforme de la intensidad a lo largo de ambos tipos de realización percibida explicaría esta 
combinación de características acústicas. Por lo tanto, el centro de gravedad en las comunidades estudiadas sería un parámetro que informaría sobre la distribución de la energía a lo largo de la realización percibida pero que no sería en sí mismo determinante -puesto que recoge características de la intensidad media y máxima de la realización-en la percepción de uno u otro sonido.

\subsection{Relación entre parámetros}

Hasta aquí hemos considerado por separado los factores que pueden afectar la percepción de una u otra fricativa. Sin embargo, las investigaciones llevadas a cabo anteriormente en este campo ${ }^{39}$ sugieren que es más factible que sea una combinación de parámetros la responsable de las diferentes percepciones en el ámbito de las fricativas. A continuación, ponemos en correspondencia aquellos factores cuya relación bilateral con la realización percibida ha producido resultados más alentadores, en la sección anterior, en el sentido de la distinción entre /s/ y / $\theta /$.

3.3.1. Intensidad y otros parámetros. A la vista de los resultados anteriores, la intensidad -en las dos mediciones que hemos efectuado relacionadas con este parámetro: la intensidad media y la intensidad máxima- se muestra como la magnitud más influyente en la distinción de los sonidos sibilantes del español en los hablantes estudiados. Es asimismo probable que la modificación de este parámetro esté conectada directamente con los procesos de acomodación a corto plazo de los hablantes rurales que tratan de realizar un sonido estridente -a partir de su habitual realización mate- en los contextos de lectura más formales. Por estos motivos, se analiza a continuación en profundidad la intensidad, observando sus conexiones con otras magnitudes.

39 Ya D. Whalen ("Perception of the English /s/ - / / distinction relies on fricative noises and transitions, not on brief spectral slices", Journal of the Acoustic Society of America, 1991, núm. 90, p. 1776) indicaba que "the multiplicity of cues to speech distinctions continues to be the central problem in speech perception" y se sorprendía de cómo el ser humano, como usuario de la lengua, se desenvuelve en esta multiplicidad de parámetros con aparente facilidad, bien como productor de sonido, bien como perfecto decodificador. C. Shadle y C. Scully ("An articulatory-acoustic-aerodynamic analysis of [s] in VCV sequences", Journal of Phonetics, 23, 1995, 53-66) llegan incluso a poner en relación parámetros de orden articulatorio, acústico y aerodinámico para una mejor comprensión de la [s] en contextos intervocálicos. 
Al poner en correspondencia la intensidad media y la intensidad máxima de las relaciones percibidas en los hablantes urbanos (véase Figura 6), se observa una fuerte y positiva correlación lineal (Pearson 0,943; sig. $=, 000)$ entre el valor del pico del espectro -o intensidad máxima- y la intensidad media de la fricativa. Los valores proporcionados por estas magnitudes establecen dos fronteras claras:

1) Aquellas realizaciones que superaron los $64 \mathrm{~dB}$ de intensidad media fueron percibidas como [s]; mientras que las realizaciones con menor intensidad media se identificaron como $[\theta]$.

2) Las realizaciones con una intensidad máxima (medida en el espectro) inferior a $30 \mathrm{~dB}$ fueron clasificadas como $[\theta]$, en tanto que las que fueron claramente percibidas como una sibilante estridente obtuvieron valores de este parámetro por encima de $30 \mathrm{~dB}$.

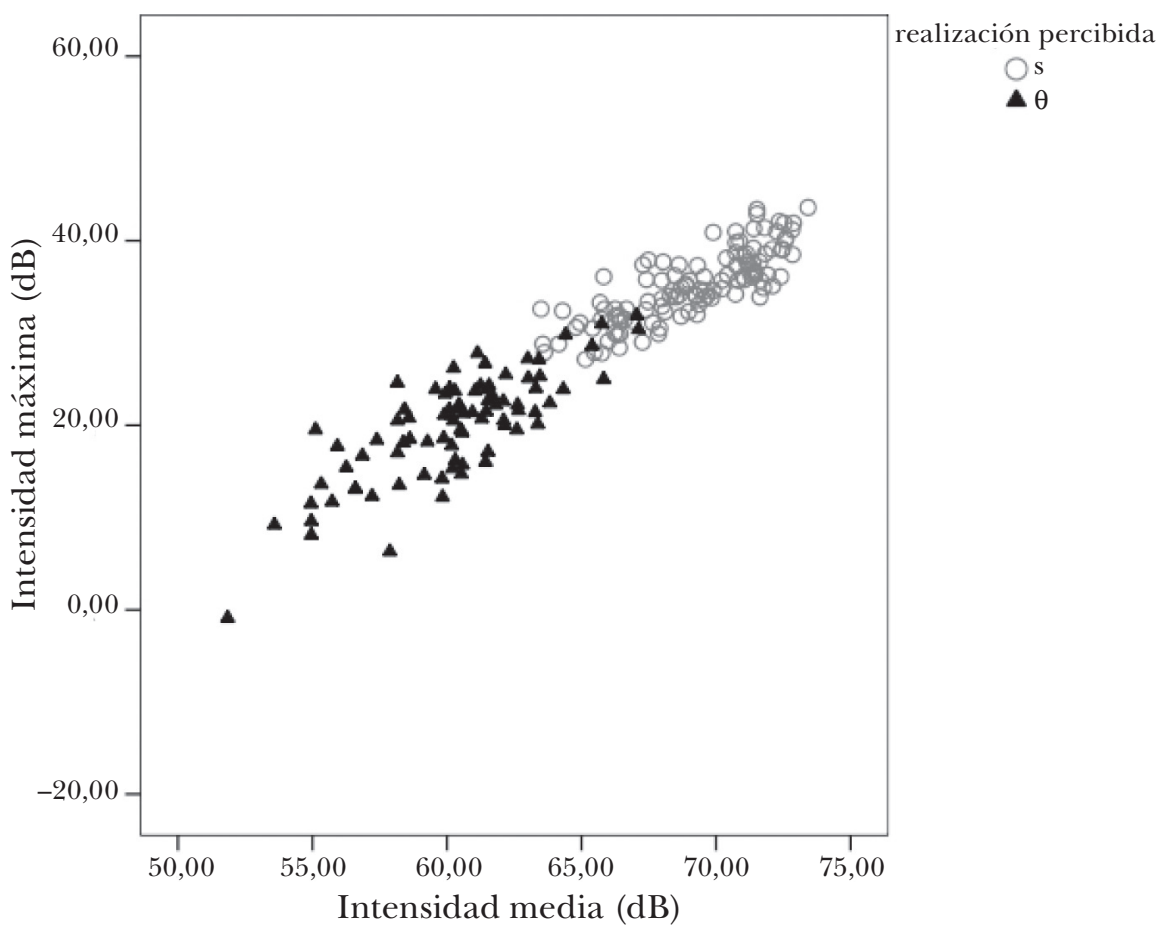

Figura 6. Gráfico de dispersión de la intensidad media y el pico del espectro de las realizaciones percibidas como /s/ y / $\theta /$ en los hablantes urbanos. 


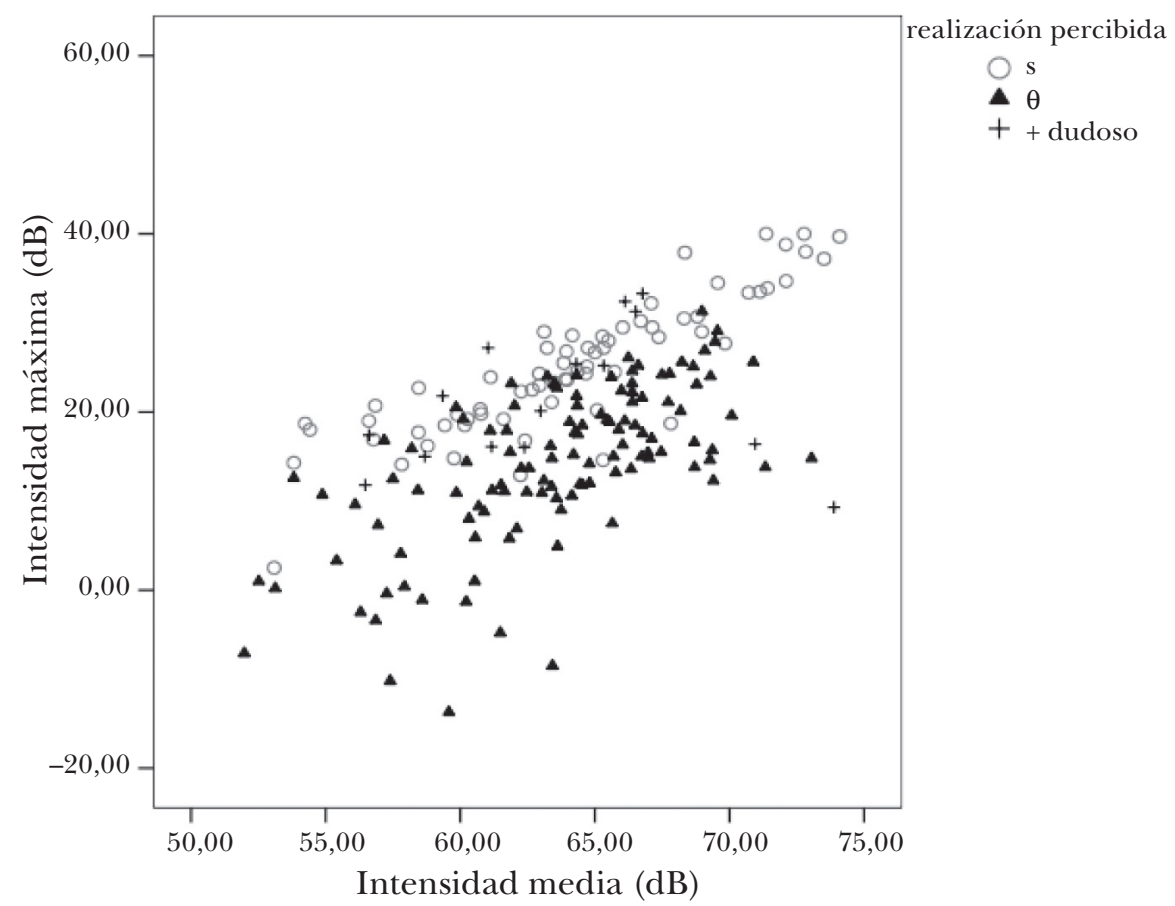

Figura 7. Gráfico de dispersión de la intensidad media y la intensidad máxima de las realizaciones percibidas como $/ s /$ y $/ \theta /$ en los hablantes rurales.

$\mathrm{Al}$ analizar las mismas variables en las realizaciones de los hablantes rurales se observa un patrón más confuso de dispersión de los datos (véase Figura 7). Llama la atención la mayor intensidad de las realizaciones percibidas como [ $\theta]$, que supera en muchos casos el límite fijado por las realizaciones de los hablantes urbanos. También destaca la baja intensidad -en algunos casos por debajo incluso de $55 \mathrm{~dB}$ de media- de las realizaciones percibidas como [s]. Respecto al pico del espectro, los valores de las realizaciones percibidas como una u otra sibilante también presentan una distribución sensiblemente diferente a la que observamos en los hablantes procedentes de la ciudad. Aparecen valores de pico del espectro más bajos para la $[\theta]$ que los observados en los hablantes urbanos. Los valores de pico del espectro (o intensidad máxima) en las realizaciones percibidas como [s] , en cambio, se mantienen generalmente por encima de los $20 \mathrm{~dB}$. Las realizaciones dudosas se reparten desigualmente a lo largo de la gráfica.

Si comparamos los datos correspondientes a las realizaciones de los hablantes urbanos (Figura 6) con los obtenidos de las realizaciones de los hablantes rurales (Figura 7), se aprecia con 
claridad la diferente distribución de los valores de intensidad media y máxima: en los hablantes urbanos la polarización de los datos es manifiestamente mayor.

El estilo afecta desigualmente a las dos poblaciones consideradas. En los hablantes urbanos, el incremento de la formalidad no implica un aumento de la intensidad de la realización percibida como [s]. Las realizaciones de los hablantes rurales, por el contrario, aumentan sus valores de intensidad conforme aumenta la formalidad del discurso (véase Figura 8).
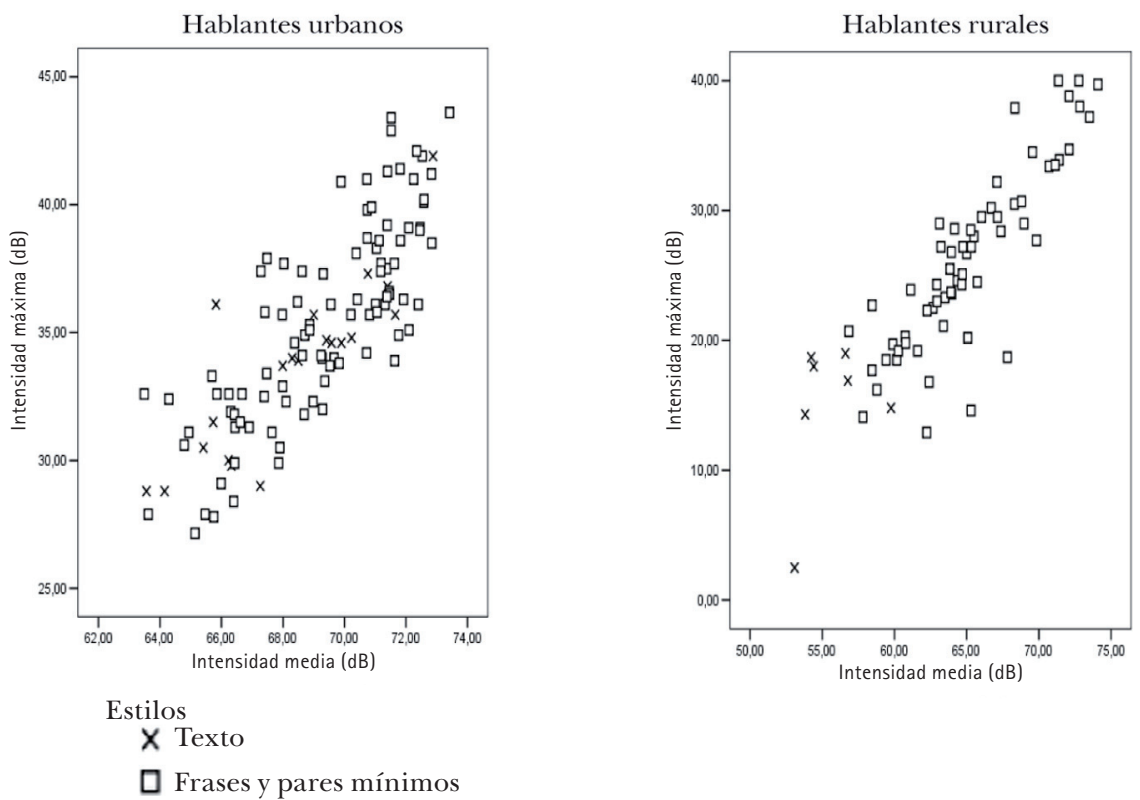

Figura 8. Efecto del estilo en los valores de intensidad de las realizaciones de hablantes rurales y urbanos percibidas como [s].

Los datos estudiados hasta aquí muestran que la intensidad -máxima en ambos grupos y media en los hablantes urbanoses un parámetro significativo para diferenciar perceptivamente $[\mathrm{s}]$ y $[\theta]$ en la comunidad estudiada. Para comprobar este extremo, hemos llevado a cabo un análisis discriminante. Se ha elegido este método por dos razones: en primer lugar, la realización percibida es una variable categórica cuyas variantes son mutuamente excluyentes; en segundo lugar, la clasificación de los datos obtenidos en la observación permite la clasificación previa al análisis de las ocurrencias en uno u otro grupo ${ }^{40}$. Así

${ }^{40}$ Para una explicación detallada del análisis discriminante, véase J. Gil Flores, E. García Jiménez y G. Rodríguez, Análisis discriminante, 
pues, la variable de agrupación que se ha seleccionado es la 'realización percibida', con el objetivo de identificar los factores más determinantes en la percepción de una u otra sibilante.

En la Tabla 14 se exponen los resultados del análisis en el grupo rural. Todas las variables que aparecen en el análisis son significativas $(\mathrm{sig} .=, 000)$. Las variables que producen la mejor combinación son la intensidad y la frecuencia de inicio de la fricación:

TABLA 14

Análisis discriminante de las variables que afectan las realizaciones de los hablantes rurales

\begin{tabular}{|l|c|c|c|}
\hline Paso & Tolerancia & F de salida & Lambda de Wilks \\
\hline 1. Intensidad máx. & 1,000 & 37,2117 & \\
\hline 2. Intensidad máx. &, 538 & 59,440 &, 996 \\
Intensidad media &, 538 & 16,863 &, 726 \\
\hline 3. Intensidad máx. &, 537 & 45,738 &, 731 \\
Intensidad media &, 504 & 23,924 &, 620 \\
Frecuencia inicio fricación &, 903 & 23,865 &, 620 \\
\hline
\end{tabular}

* El número máximo de pasos en el análisis es 8, la F parcial mínima para entrar es 3,84 y la mínima para salir, 2,71.

En la Tabla 15 se muestran los resultados para las realizaciones de los hablantes urbanos, con el fin de comprobar si la jerarquía varía considerablemente según el origen de los informantes. Como en el grupo anterior, todas las variables que aparecen en el análisis son significativas $($ sig. $=, 000)$ :

TABLA 15

Análisis discriminante de las variables que afectan las realizaciones de los hablantes urbanos

\begin{tabular}{|l|c|c|c|}
\hline Paso & Tolerancia & F de salida & Lambda de Wilks \\
\hline 1. Intensidad media & 1,000 & 516,625 & \\
\hline 2. Intensidad media &, 362 & 19,905 &, 286 \\
Intensidad máx. &, 362 & 12,180 &, 276 \\
\hline
\end{tabular}

Hespérides, Madrid, 2001; B. Visauta Vicanua y J.C. Martorí Cañas, Análisis estadístico con SPSS para Windows ${ }^{\circledR}$. T. 2: Estadística multivariante, McGraw Hill, Madrid, 2003; y A. FIELD, Discovering stadistics using SPSS, SAGE, London, 2005. 
TABla 15 (Conclusión)

\begin{tabular}{|l|c|c|c|}
\hline Paso & Tolerancia & F de salida & Lambda de Wilks \\
\hline 3. Intensidad media &, 362 & 19,306 &, 270 \\
Intensidad máx. &, 361 & 12,426 &, 661 \\
Frecuencia inicio fricación &, 990 & 11,563 &, 260 \\
\hline 4. Intensidad media &, 357 & 21,113 &, 264 \\
Intensidad máxima &, 360 & 10,650 &, 251 \\
Frecuencia inicio fricación &, 989 & 10,559 &, 251 \\
Frecuencia máxima intensidad &, 985 & 6,297 &, 245 \\
\hline
\end{tabular}

Hay diferencias notables en los correlatos de $[\mathrm{s}]$ y $[\theta]$ percibidos en las realizaciones de los hablantes rurales y urbanos. En ambos casos, las medidas de intensidad se sitúan en las primeras posiciones respecto a su efecto en la realización percibida. Sin embargo:

a) En los hablantes rurales, la intensidad máxima es la primera variable introducida en el modelo. En los hablantes urbanos es la intensidad media el primer parámetro seleccionado en el análisis discriminante.

b) La tolerancia mide la proporción de varianza de una variante independiente que no está explicada por el resto de variables. Por lo tanto, una tolerancia baja implica un alto grado de correlación entre las variables incluidas en un determinado paso del análisis. Si es alta, la correlación entre esa variable y el resto será menor. El aumento de la tolerancia de las variables relativas a la frecuencia al incluirlas en el análisis indica que mantienen escasa relación con las variables relacionadas con la intensidad.

c) En estrecha relación con la tolerancia, el valor de $\mathrm{F}$ de salida "permite valorar el descenso en la discriminación si una variable fuera extraída del conjunto de las ya seleccionadas" ${ }^{1}$. Conforme mayor sea el valor de este estadístico, mayor será su contribución a la discriminación de los grupos observados. En nuestro estudio vemos que, a lo largo de los diferentes pasos propuestos para cada grupo, obtienen un valor de F de salida más alto las variables de intensidad máxima (en los hablantes rurales) e intensidad media (en los urbanos), lo que las identip. 50 .

41 J. Gil Flores, E. García Jiménez y G. Rodríguez Gómez, op. cit., 
fica como los parámetros más significativos para explicar la variación observada en cada grupo.

d) Por último, el estadístico lambda de Wilks mide las diferencias entre grupos debidas a varias funciones discriminantes; esto es, calcula la habilidad de las variables para discriminar entre grupos. Valores de lambda de Wilks próximos a cero implican una alta discriminación de los grupos considerados ${ }^{42}$. En los hablantes urbanos, el valor de lambda de Wilks se mantiene bajo en todos los pasos del análisis, lo que indica que los grupos -en este caso, las diversas realizaciones percibidas- muestran diferencias significativas para las variables consideradas y que la explicación de la variación es fuerte. Por el contrario, los valores de lambda de Wilks en el análisis correspondiente al grupo de hablantes rurales son altos, por lo que podemos considerar que los grupos son similares y que, por tanto, la explicación de la variación es débil.

El análisis discriminante confirma el efecto de la intensidad en la percepción de uno u otro sonido y el diferente comportamiento de los dos parámetros de intensidad considerados. En los hablantes urbanos (véase Tabla 2 y Figura 6), la intensidad media y, en menor proporción, la máxima (véase Tabla 4) explican satisfactoriamente la variación perceptiva observada. En los hablantes rurales (véase Tabla 3 y Figura 7), la explicación de la diferente percepción de $[\mathrm{s}]$ y $[\theta]$ es igualmente satisfactoria, aunque débil, y, pese a que los parámetros relativos a la intensidad siguen ofreciendo la mejor explicación de la variación, ahora la intensidad máxima es el parámetro acústico que mejor sustenta el modelo teórico.

\section{ConClusión}

Tras el análisis detallado de las realizaciones obtenidas, se constata entre los hablantes jóvenes con instrucción superior y ori-

${ }^{42}$ Lo que implica que "los grupos centroides están separados y son muy distintos con relación a la dispersión que existe dentro de los grupos" (M.T. Rivas Moya, F. Rius Díaz y M.R. Martínez Arias, Análisis discriminante: una aplicación del método "stepwise", Universidad, Málaga, 1990, p. 35). 
gen urbano un claro patrón de distinción meridional ${ }^{43}$. En los hablantes rurales, el gran número de casos de reducción no sibilante en el primer estilo -la lectura de un texto narrativodisminuye significativamente en las frases y desaparece en los pares mínimos. Este hecho nos indica, por una parte, la fuerte tendencia a la reducción no sibilante de la variedad rural y, por otra, la conciencia de los hablantes acerca del hecho de que la indistinción se considera un marcador de origen rural que procuran eliminar en estilos formales.

En relación con el análisis acústico de los segmentos estudiados, la intensidad -tanto en su valor medio como máximo- se confirma como parámetro decisivo para la discriminación de sonidos sibilantes, relegando la frecuencia de inicio de la fricación y la frecuencia a la que se alcanza la máxima intensidad a un lugar secundario. En esta muestra, el centro de gravedad y la duración de la realización no explican la variación observada.

El patrón habitual de realización de los informantes seleccionados -que, como hemos observado, se relaciona con su origeninfluye en los mecanismos de producción de sibilantes mates y estridentes. Los hablantes urbanos habituados a la distinción de sibilantes dotan a sus realizaciones de unos valores determinados de intensidad media y máxima que delimitan la percepción de uno u otro sonido ${ }^{44}$. Los hablantes de origen rural, con un patrón habitual de realización de reducción de sibilantes a favor del sonido mate, utilizan igualmente la intensidad -en este caso, máxima y media- para diferenciar $[\mathbf{s}]$ y $[\theta]$, aunque las fronteras entre ambos sonidos no aparecen tan delimitadas como en los hablantes urbanos.

Llama especialmente la atención el hecho de que la magnitud acústica que mejor explica la discriminación de sibilantes en los hablantes urbanos sea la intensidad media y en los rurales la máxima. Es posible que los hablantes habitualmente reductores no posean el dominio articulatorio suficiente como para aumentar la intensidad media (a lo largo de toda la realización) del segmento sibilante, pero sean conscientes, en cierta forma,

43 Dato esperable teniendo en cuenta los ya obtenidos por J.A. Villena acerca de la estratificación educacional y gradación de edad en el uso del patrón convergente.

${ }^{44}$ Cuando la intensidad media de la realización superó los 64 dB y la intensidad máxima (medida en el espectro) los $30 \mathrm{~dB}$, las realizaciones fueron percibidas como $[\mathrm{s}]$; cuando los valores de magnitudes fueron inferiores, la percepción determinó un sonido mate. 
de que las realizaciones deben aumentar su intensidad para que el interlocutor las perciba como un sonido estridente, adaptándose de esta manera al patrón de realización distinguidor que exige el contexto formal. El aumento de la intensidad máxima de la realización constituye, así pues, una solución alternativa para incrementar la intensidad de la realización, lo que provoca en el receptor una percepción estridente del sonido emitido.

En consecuencia, parece probado que los sonidos sibilantes de las variedades estudiadas se organizan en un continuo acústico y articulatorio de realizaciones en el que ciertas magnitudes variables -especialmente la intensidad-configuran su discriminación perceptiva. Igualmente, se observan diferentes estrategias de diferenciación de sibilantes en función del patrón de realización habitual del hablante, que se confirma como distinguidor meridional en la ciudad y como reductor en entornos rurales. En próximos estudios se ampliará el número de jueces de la percepción emitida y se trabajará con variantes modificadas artificialmente con el objeto de delimitar en mayor grado el funcionamiento de estos parámetros en relación con la percepción obtenida. 


\section{APÉNDICE I}

Texto

Se cuentan muchas historias raras sobre los extranjeros que visitan España. Los pobrecillos se meten en un montón de líos. Por ejemplo, me contaron la historia de una chica que estaba en España para jugar al golf en la costa. A pesar de que jamás había tenido ningún problema, un día bajó al centro en pleno mes de julio y una gitana le dio un buen susto. Se le acercó mientras ella estaba distraída hablando con su amigo Jesús. La asaltó de repente y le dijo que tenía que elegir: o le daba todo el dinero que llevaba o la iba a rajar. Justo cuando la mujer iba a coger todo el dinero de la chica, una maceta cayó muy cerca de la gitana, que se pegó un susto de muerte. La chica aprovechó para escapar rápidamente.

A pesar de estos inconvenientes, si hay algo que les gusta hacer a los extranjeros en España es salir por las noches. Muchísimos turistas me han preguntado si es mejor salir los viernes por la noche o los sábados. Desde que han quitado el botellón, yo prefiero salir los viernes, porque los sábados sale mucha gente. Además los bares han aprovechado para subir las copas y ya no se puede salir los dos días como antes. Si quieres salir viernes y sábados, tienes que ir al Parque, pero allí estás muy lejos de todo y no hay ni un kiosco donde comprarte chucherías. Además de que va la peor gente de Málaga, ésos que se creen muy chulos. Este fin de semana llevé a un amigo mío checo y le han hecho un buen chichón sólo por andar mirando a una chica que estaba allí con su novio.

Muchos turistas aprovechan para ligar. A un chico le gustaba una amiga mía y quedaron para ir al cine. Después del cine, ya era súper tarde. Estaban ya cerca de la casa de ella y el chico estaba muy nervioso y serio. Básicamente se sentía incapaz de hacer nada. Estaba empapado en sudor. Sólo sabía que la quería besar. Cuando llegaron, ella le dijo que pasase y que se sentase en una silla que había junto a la mesa de la cocina. En ese momento él la besó. Ella me contó que aquel beso fue el más dulce que le habían dado en su vida. Creo que todavía siguen saliendo.

Algunos turistas deciden quedarse y buscar un trabajo. Mi amigo Fernando hace dos semanas encontró empleo, aunque le costó mucho. Cuando supo que tenía la entrevista, el pobre consultó su zodíaco para ese día y hasta fue a comprarse zapatos nuevos expresamente para la cita. Iba a ser una cena en un restaurante de la zona más cara la ciudad. Recitó de memoria todo lo que quería decir antes de entrar en el restaurante, pero sabía que a fin de cuentas todo dependía del azar. Había hablado con mucha gente y ni Zutano ni Mengano le habían sabido decir una palabra sobre cómo sería la entrevista. Pensó que nadie nace para este tipo de situaciones. En cuanto llegó, tuvo que pedir un vaso de zumo para poder articular palabra, de tan nervioso que estaba. Pero todo mereció la pena porque finalmente le dieron el trabajo y ahora está muy contento.

Y es que ser extranjero en España no es fácil, pero con un poco de suerte, las cosas pueden terminar yéndote muy bien. 
Frases

Si la rosa es ella, mejor así.

Si la roza, es ella, mejor así.

Esta situación la poetiza la poetisa sin problemas.

Esta situación la poetisa la poetiza sin problemas.

La pelota que viene rasa es más difícil de parar.

El perro, si tiene raza es más difícil de encontrar.

Dice que si la riza le quedará mejor la falda.

Dice que la risa le quedará mejor que la pena.

Me gusta el sumo; es dulce cuando ganas.

Me gusta el zumo; es dulce cuando acabas.

Que yo sepa, el vino está en la cepa antes que en la mesa.

No ceso de perder el seso por el sexo.

¿La ves en el súper? Nunca. Tarda mucho.

¿La vez en el súper? Nunca. Tarda mucho.

Meses y meses sin parar de mecer al chico.

Meces y meces sin parar de mecer al chico.

La puja por la púa del famoso guitarrista se disparó.

Rajo el vestido de raso porque ya me he hartado de él.

La rea reza frente a su reja todos los días.

Ese pantano checo está seco.

Quiero una cena frente al río Sena.

Aproveché que habíamos quedado por la noche para llevarle chucherías a mi chica.

Dando clase tienes que aguantar muchas chulerías de los chavales.

Me gusta la costa de Málaga.

Los rastas se llevaron un buen susto cuando la policía registró su puesto.

Cuando quedo en ese restaurante con mis amigos, siempre termino hasta arriba de comer, salgo apestando a whisky y me voy a casa hecho misto. 
Hasta que fue con su tío Genaro a finales de julio, aquella gitanilla nunca había bajado al río a coger truchas.

Dijo que sólo había estado una vez con su primo Juan para jugar al escondite.

¡Basta ya de andar por ahí rajando y chismorreando de los demás!

Hay que elegir con cuidado entre un colegio estatal y uno privado para tus hijos.

\section{PARES Mínimos}

rasa / raja / raza / racha / rasta

coser / coger / cocer / costa

tesa / teja / techa / tea / testa

miso / mijo / mío / micho / misto

reja / reza / rea / resta

pisa / pija / picha / pizza / pía / pista

puja / púa

poso / pocho / pozo / puesto

pesada / pechada / apesta

rosa / roza / roja / rocha / roa

techado / tejado / tezado / testado

sumo / zumo / jumo / humo

mucha / musa

checo / seco

cena / Sena 